\title{
The Effect of Phosphorus Reduction and Competition on Invasive Lemnids: Life Traits and Nutrient Uptake
}

\author{
Joëlle Gérard and Ludwig Triest \\ Plant Biology and Nature Management (APNA), Vrije Universiteit Brussel, Pleinlaan 2, 1050 Brussels, Belgium \\ Correspondence should be addressed to Joëlle Gérard; jgerard@vub.ac.be
}

Received 14 December 2013; Accepted 3 January 2014; Published 10 February 2014

Academic Editors: R. B. Peterson and T. L. Weir

Copyright (C) 2014 J. Gérard and L. Triest. This is an open access article distributed under the Creative Commons Attribution License, which permits unrestricted use, distribution, and reproduction in any medium, provided the original work is properly cited.

\begin{abstract}
Introduction of invasive macrophytes often leads to competition with native species or with already established invasive species. Competition between invasive species in multiple-invaded systems is expected to be particularly high, especially when they share growth form and position in the water column. We performed indoor experiments between invasive free-floating Lemna minuta and Landoltia punctata in monocultures and mixtures under a phosphorus gradient concurring with hypereutrophic, eutrophic, mesotrophic, and oligotrophic conditions. Our results showed that a phosphorus reduction from hypereutrophic to eutrophic had important negative impacts on the relative growth rate (RGR) of both species. A further reduction to mesotrophic condition did not alter either species RGR. However, species strategies and nutrient uptake differed. Both intra- and interspecific interference occurred; however, the intensity differed between phosphorus concentrations. Difference in RGR (RGRD) showed L. minuta to gain at high phosphorus levels, while a reduction favoured L. punctata. In oligotrophic condition, either species hardly produced new daughter fronds. Our results are useful to (1) understand the effects of phosphorus and setting target values in the process of eutrophication reduction and (2) diminish the impacts of invasive lemnids since a water column phosphorus reduction would prevent large impacts.
\end{abstract}

\section{Introduction}

In the last 100 years, a variety of invasive aquatic plants have been introduced to Europe due to increasing travel and trade [1]. These introductions often lead to competitive interactions with native species and with already established alien species [2]. Numerous studies on competition have demonstrated competitive superiority of alien plants over native plants due to their higher growth rates $[3,4]$. However, competition between alien species has rarely been explored. A high level of competition might be expected, especially between related species with shared growth form, occurring in the same position in the water column $[5,6]$.

Eutrophication of aquatic ecosystems is a second major threat to freshwater biodiversity. It plays an important facilitating role in the invasion process $[7,8]$, since it can increase the invasibility of water bodies [9] and change the competitive balance between plant species leading to changes in species composition [10]. Eutrophication of most freshwater ecosystems is enhanced by phosphorus inputs [11], since $\mathrm{P}$ is often the limiting element for freshwater macrophytes [12]. P can occur as soluble reactive $\mathrm{P}$ (SRP), particulate organic $\mathrm{P}$, and soluble organic $\mathrm{P}$. P is delivered to aquatic ecosystems as a mixture of these forms, but aquatic plants only take up $\mathrm{P}$ in inorganic form, primarily as orthophosphate [13].

Several studies have shown that a high resource availability boosts the performance of invasive species $[7,8$, 14], since successful invaders are capable of using limiting resources more efficiently than less invasive species, leading to higher relative growth rates (RGRs) [15]. However, most of these studies were performed only in high nutrient levels [16] because species with high competitive performance are known to occur in nutrient-rich areas and not in low-nutrient areas [17]. Reducing phosphorus levels is a powerful tool to reduce eutrophication [12] and might help in controlling the productivity and competitiveness of invasive macrophytes, possibly leading to changes in plant community composition. It is crucial that the latter is confirmed by competition experiments in low and high nutrients to examine whether invasiveness of plants is reduced after a water column nutrient 
reduction. Since competitiveness for nutrients should incorporate a plant's capability to use that nutrient for growth and its ability to store nutrients when its concentration is low [18], we studied morphology and life-traits, as well as nutrient storage in plant tissues.

Many alien plant species owe their invasive success to traits related to morphology, physiology, and reproduction [19]. Various studies have attempted to identify common traits associated with invasiveness, to better understand and predict the level of species invasiveness [20,21]. Even though it is apparent that one set of traits is not applicable to every invasive plant, the search for traits is still crucial [19]. However, studies should focus on related species with the same growth form, since similar species may use different traits to promote invasiveness $[19,22]$.

Lemnids, commonly known as duckweed, are small fast growing aquatic plants and are known to be a symptom of high-nutrient concentration in small water bodies [23]. Lemnids develop dense mats when enough nutrients and light are available. These mats reduce submersed plant abundance by eliminating sunlight penetration and interfere with gaseous exchange, reducing fish populations [24, 25]. Duckweeds are P-hyperaccumulators and can use internally stored phosphorus for growth when it is no longer available $[26,27]$. Hyperaccumulation can present advantages for the invasion of lemnids and can lead to higher competition with other invasive lemnid species. In this study, we used two invasive lemnid species: Lemna minuta Kunth (least duckweed) and Landoltia punctata Les \& Crawford (dotted duckweed). Lemna minuta is native to North and South America and is currently an invasive alien species in Europe including Belgium [28]. Landoltia punctata originates from Australia and Southeast Asia and has invaded several European countries [29]. The species is not present in Belgium but has been reported in The Netherlands [30]. Since lemnids rely on the water column for nutrients, studies on water column nutrient change might help in understanding the effects of phosphorus and setting target values in the process of eutrophication reduction [31]. These results will show whether L. minuta and L. punctata are able to invade habitats ranging in trophic condition, or only high nutrient loaded water columns. Results will also show whether L. punctata should be considered for the Belgian watch or alert list for invasive species.

The present study aimed at investigating competitive outcomes between the two invasive species Lemna minuta and Landoltia punctata growing in varying $\mathrm{P}$ concentrations representing hypereutrophic, eutrophic, mesotrophic, and oligotrophic conditions. The main purposes of this study are to investigate (1) the intraspecific and interspecific competition between the invasive lemnids, (2) the life-history traits that enhance the invasive potential of the most invasive species, and (3) the effect of a phosphorus reduction on plant growth, competition, and plant strategies.

\section{Materials and Methods}

Lemna minuta was collected from a nature area "Kalkense Meersen" in Belgium, and L. punctata was obtained from the National Botanical Garden. A single plant was cultured for each species in full strength Hoagland's solution to obtain stock cultures. Plants were cultivated in glass aquaria in a temperature-controlled growth room at $25 \pm 2^{\circ} \mathrm{C}$ by day, $19 \pm 2^{\circ} \mathrm{C}$ by night under controlled photoperiod (16/8 hr day/night), and PAR approximately between 63 and $72 \mu \mathrm{mol} \mathrm{m}{ }^{-2} \mathrm{~s}^{-1}$.

We performed four indoor experiments, corresponding to the trophic states as recognized in limnology [32]: oligotrophic (0-10 $\left.\mu \mathrm{g} \mathrm{P} \mathrm{L}^{-1}\right)$, mesotrophic $\left(10-30 \mu \mathrm{g} \mathrm{P} \mathrm{L}^{-1}\right)$, eutrophic $\left(30-100 \mu \mathrm{g} \mathrm{P} \mathrm{L}^{-1}\right)$, and hypereutrophic $\left(>100 \mu \mathrm{g} \mathrm{P} \mathrm{L}^{-1}\right)$, with the latter being used as a control. The experiments were performed from August 2010 to March 2011 in a single temperature-controlled room at the Vrije Universiteit Brussel. For the hypereutrophic experiment, a standard Hoagland and Arnon [33] solution was used $\left(\mathrm{P}=30.97 \mathrm{mg} \mathrm{L}^{-1}\right)$. For the other experiments, we used Hoagland and Arnon solution lacking phosphorus [33] and added $\mathrm{KH}_{2} \mathrm{PO}_{4}$ such that the phosphorus concentration concurred with the maximum value of each trophic state. To assess the importance of intra- and interspecific interactions, each experiment followed a complete additive design [34]. The initial frond number for L. minuta: L. punctata was $0: 14,0: 28,14: 28,14: 14,28: 28,28: 14,28: 0,14: 0$, and each combination replicated 5 times. A density of 14 consisted of 4 similar sized mother fronds, each with 2 daughter fronds, and 1 mother frond with 1 daughter frond (Figure 1). A density of 28 contained twice these groups. Each combination of plants was placed in a $600 \mathrm{~mL}$ glass beaker filled with $250 \mathrm{~mL}$ solution, resulting in 40 beakers. Beakers were randomly placed in a growth room under identical conditions as during cultivation. Nutrient solutions were renewed every other day during 20 days, after which all plants were separated according to species. At the end of the eutrophic, mesotrophic, and oligotrophic experiments, digital images were taken to estimate the total frond area of each species. Plants were placed in a black container to minimize background effects, filled with an equal amount of water, placed at a constant distance from the camera. This method of estimation was chosen since it is noninvasive or damaging [35] and allows different parameters to be determined using appropriate user-friendly software [36]. Plant pixels were isolated from the total digital image in Adobe Photoshop 7.0, and the total frond number was counted in Image J.

In addition, we determined species traits by randomly selecting 15 clusters of fronds per species in each beaker and determining the number of fronds per cluster and the longest root per cluster. For the oligotrophic experiments all frond clusters were analysed since the final number of clusters was lower than 15 . Plants were then oven-dried at $70^{\circ} \mathrm{C}$ for 48 hours and weighed.

Particulate organic nitrogen (PON) and carbon (POC) concentrations in plant tissue were analyzed simultaneously using a Flash EA 1112 (Thermo) elemental analyzer [37], at the Vrije Universiteit Brussel. Known amounts of samples $( \pm 10 \mathrm{mg})$ are packed in tin cups and placed sequentially in the sampler of the analyzer. Samples are first injected under 


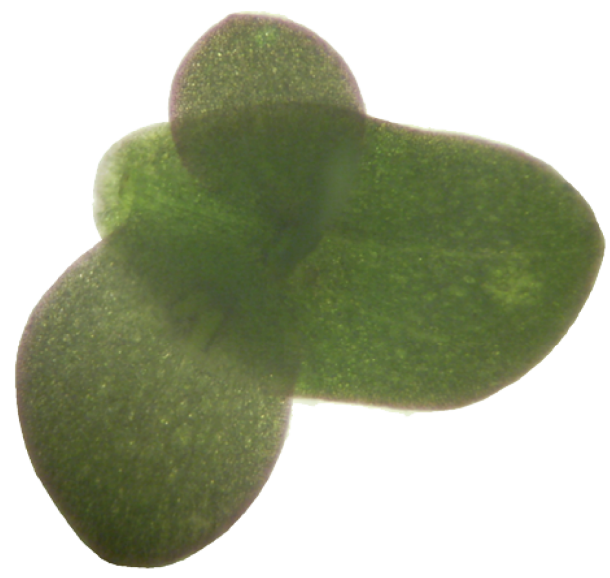

FIGURE 1: Underside of L. punctata group of fronds consisting of a mother frond and two clonally produced daughter fronds. The length of the mother frond is approximately $0.4-0.7 \mathrm{~cm}$.

a continuous $\mathrm{He}$ flow in a combustion oven $\left(1020^{\circ} \mathrm{C}\right)$ with a pulse of oxygen (flash combustion) where organic $\mathrm{C}$ and $\mathrm{N}$ are converted to $\mathrm{CO}_{2}, \mathrm{~N}_{2}$, and nitrogen oxide gasses. Gasses then sequentially pass through a reduction oven filled with $\mathrm{Cu}\left(640^{\circ} \mathrm{C}\right)$ where all nitrogen oxides are reduced to $\mathrm{N}_{2}$, through a water trap, and through a GC column where $\mathrm{CO}_{2}$ and $\mathrm{N}_{2}$ gasses are separated before reaching a thermal conductivity detector. An acetanilide standard was used to make 6-point standard curves. Samples are analyzed randomly with blanks (empty tin cups) and standards.

2.1. Statistical Analysis. The differences total frond area, number of fronds per cluster, total number of fronds, root length, and tissue nutrient concentration between species and between nutrient levels were analyzed with nonparametric Mann-Whitney $U$ test and Kruskal-Wallis ANOVA. To determine the effect of species, water phosphorus and species $\times$ phosphorus on biomass, N\%, and C\%, a two-way ANOVA with aligned rank transformed (ART) data was performed.

The relative growth rate (RGR) of each species was calculated according to the formula: $\mathrm{RGR}=\ln (Y / y) / t$, where $y$ is the species initial stand biomass and $Y$ the species stand biomass at the end of the experimental period $t$. The effects of competition and phosphorus reduction on RGR were analyzed using multiple linear regression leading to the equation

$$
\mathrm{RGR}_{i}=a_{i 0}+a_{i i} y_{i}+a_{i j} y_{j}+\varepsilon .
$$

The coefficient $a_{i i}$ determines the intraspecific effects of species $i$ on its own RGR, whereas $a_{i j}$ shows the interspecific effects of species $j$ on the RGR of species $i$. The constant $a_{i 0}$ indicates a constant RGR for species $i$.

We calculated and modelled relative growth rate difference (RGRD) as described by Connolly and Wayne [38]: $\mathrm{RGR}_{2}-\mathrm{RGR}_{1}(2=$ L. punctata, $1=$ L. minuta $)$. If all coefficients are zero, then no change in biomass composition occurs. If $\mathrm{RGRD}>0$, L. punctata gains more than L. minuta and vice versa if $R G R D<0$. The species with the higher RGR is considered more efficient over the course of the experiment, having a higher output per unit input [39].

\section{Results}

3.1. Relative Growth Rate. The RGRs of both species in monocultures and mixtures (Table 1) were reduced significantly when lowering nutrients from hypereutrophic to eutrophic condition. However, no significant differences were observed for either species' RGR between eutrophic and mesotrophic condition. In oligotrophic condition both species hardly grew and both species' RGRs were consequently much lower than in other trophic conditions (L. punctata mixtures: $\mathrm{H}(3, N=$ $80)=67,06 P<0.0001$, monocultures: $\mathrm{H}(3, N=40)=$ 32,98 $P<0.0001 ;$ L. minuta mixtures: $\mathrm{H}(3, N=80)=$ $67,72 P<0.0001$, monocultures: $\mathrm{H}(3, N=40)=33,00$ $P<0.0001)$

Lemna minuta always performed better in monocultures than mixed cultures except in oligotrophic condition (MannWhitney $U$ test; H $P<0.0001$, E $P<0.0001$, M $P<0.001$ ), while L. punctata showed no difference between monocultures and mixtures except in hypereutrophic condition (Mann-Whitney $U$ test: $P<0.0001$ ).

A comparison of the RGR between species indicated that L. minuta grew faster than L. punctata in monocultures except in oligotrophic (Mann-Whitney $U$ test; H $P<0.001$, E $P<0.01$, M $P<0.01$ ). In mixtures, however, both species performed similarly except in hypereutrophic condition, where L. minuta grew faster (Mann-Whitney $U$ test: $P<$ $0.0001)$.

\subsection{Strategy}

\subsubsection{Plant Traits}

Difference between Species. We found that in monocultures, both species covered a similar total area in eutrophic and mesotrophic conditions, while in oligotrophic condition, $L$. punctata covered a larger total area (Mann-Whitney $U$ test; $P<0.001)$. In mixtures, L. punctata produced a higher total area than L. minuta in all experiments (Mann-Whitney $U$ test; E: $P<$ 0.0001, M: $P<$ 0.05; O: $P<0.0001)$. Both species produced equal total amounts of fronds except in mixtures in oligotrophic condition, where L. punctata produced more fronds and in eutrophic monocultures, where L. minuta produced the most fronds. (Mann-Whitney $U$ test; E monocultures: $P<0.01$; O mixtures: $P<0.05)$. $L$. punctata possessed clusters consisting of more fronds than L. minuta in all experiments, in monocultures and mixtures, except in mesotrophic condition in mixture (Mann-Whitney $U$ test; E: mixtures $P<0.0001$, monocultures $P<0.05$; M: monocultures $P<0.01 ; \mathrm{O}$ : mixtures and monocultures $P<0.0001)$. At the end of each experiment, L. punctata had longer roots than L. minuta in mixtures and monocultures (Mann-Whitney $U$ test, $\mathrm{M}$ : mixtures and monocultures $P<$ 0.01, O: mixtures and monocultures $P<0.0001$ ).

Effect of Nutrient Reduction. A nutrient reduction from eutrophic to mesotrophic condition did not change the 
TABLE 1: RGR (mean $\pm \mathrm{SE})\left(\mathrm{g} \mathrm{g}^{-1} \mathrm{~d}^{-1}\right)$ of L. punctata and L. minuta in monocultures and mixtures in hypereutrophic, eutrophic, mesotrophic, and oligotrophic conditions.

\begin{tabular}{lcccr}
\hline & Hypereutrophic & Eutrophic & Mesotrophic & Oligotrophic \\
\hline L. punctata & & & & \\
$\quad$ Monocultures & $0.283 \pm 0.003$ & $0.133 \pm 0.008$ & $0.131 \pm 0.005$ & $0.006 \pm 0.002$ \\
Mixtures & $0.255 \pm 0.002$ & $0.134 \pm 0.005$ & $0.129 \pm 0.003$ & \\
L. minuta & & & & \\
Monocultures & $0.329 \pm 0.003$ & $0.164 \pm 0.003$ & $0.157 \pm 0.005$ & 0.001 \\
Mixtures & $0.290 \pm 0.003$ & $0.141 \pm 0.002$ & $0.126 \pm 0.006$ & $0.006 \pm 0.001$ \\
\hline
\end{tabular}

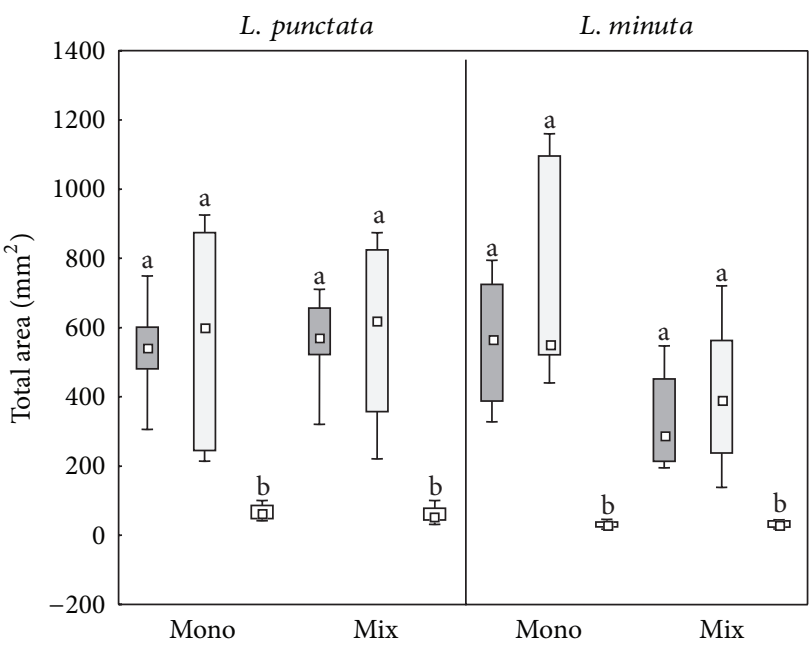

(a)

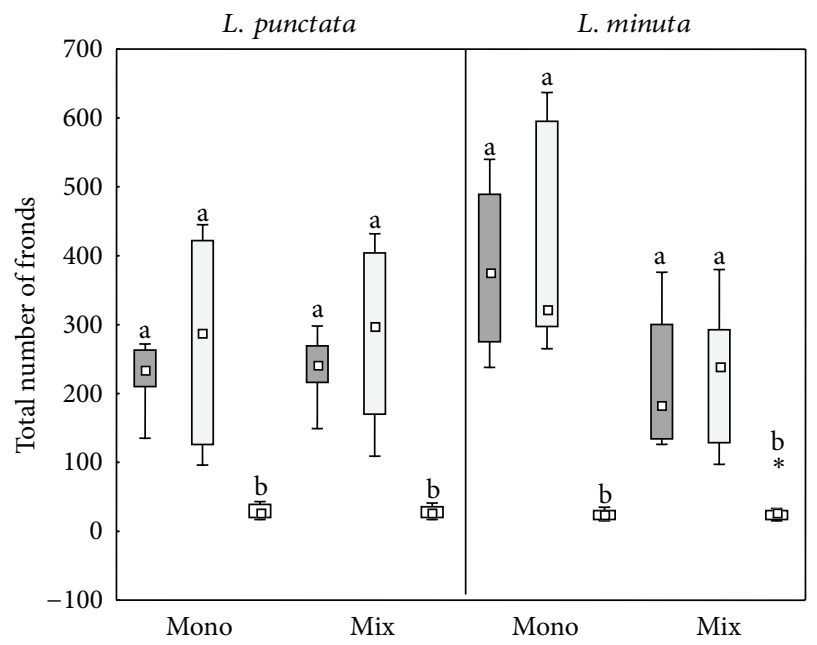

(c)

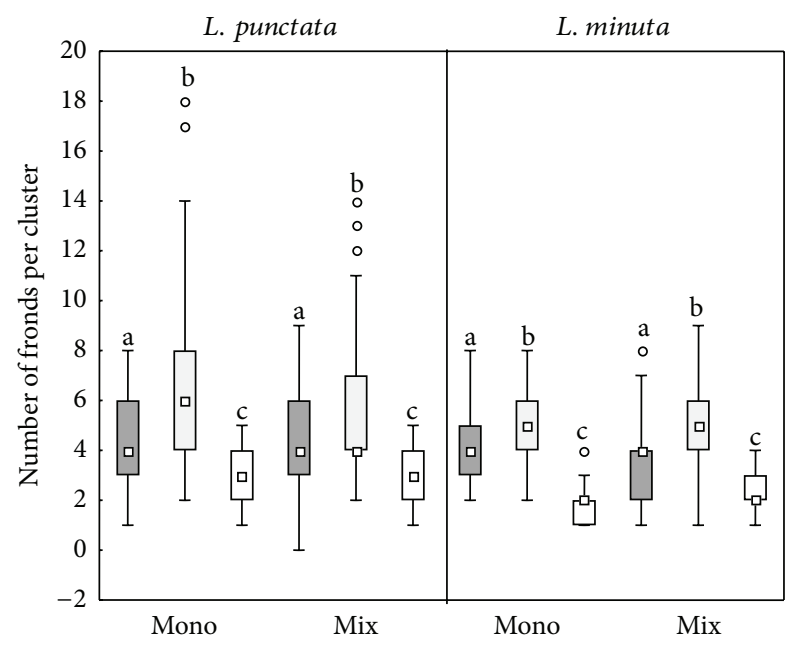

(b)

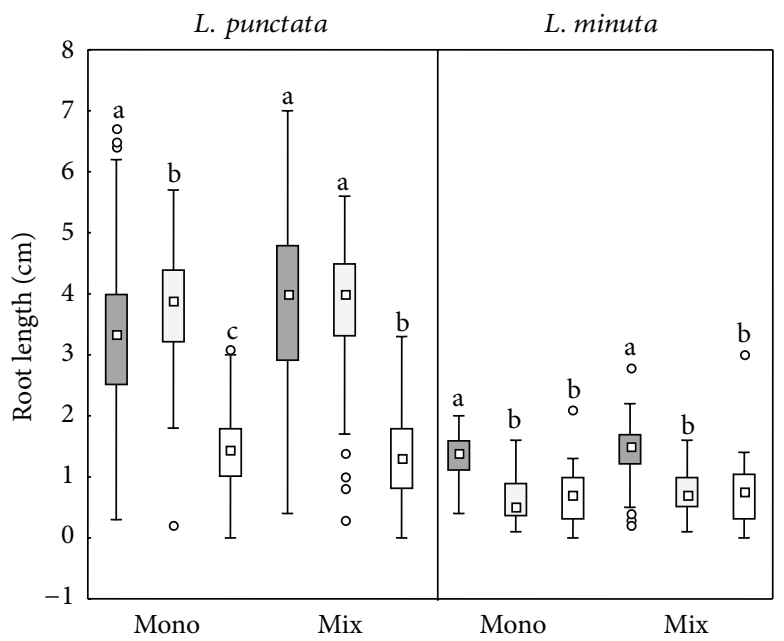

(d)

Figure 2: L. punctata and L. minuta traits after cultivation in eutrophic (dark grey), mesotrophic (light grey), and oligotrophic (white) conditions. Data were pooled for monocultures and mixtures at each phosphorus concentration. Different letters indicate significant differences between nutrient levels. $\square$ represents the median, the box represents the interquartile range, and the vertical lines indicate the minimum and the maximum non-outlier values. Outliers are represented by $\bigcirc$, extremes by $*$.

species total frond area or total frond number, in mixtures and in monocultures (Figures 2(a) and 2(c)). However, both species produced clusters of fronds consisting of a higher numbers in mesotrophic condition, in monocultures and mixtures (Figure 2(b)). In oligotrophic condition, both species produced few new fronds, thereby generating a lower frond area. A comparison of the longest root length (Figure $2(\mathrm{~d})$ ) revealed that in mixtures, L. punctata produced roots of similar length in eutrophic and mesotrophic conditions, while in oligotrophic condition, the length 
is significantly reduced. In monocultures, however, roots were significantly higher in mesotrophic condition than in eutrophic and oligotrophic conditions. L. minuta produced longer roots in eutrophic conditions and shorter roots of similar length in mesotrophic and oligotrophic conditions, in monocultures and in mixtures.

\subsubsection{Tissue Nutrient Content}

Difference between Species. When compared between species, the N\% was significantly higher for L. punctata than for $L$. minuta in all experiments except in oligotrophic condition $(\mathrm{H}: 7.23 \pm 0.05$ versus $6.62 \pm 0.06 P<0.0001, \mathrm{E}: 2.80 \pm$ 0.08 versus $2.46 \pm 0.04 P<0.01, \mathrm{M}: 2.78 \pm 0.04$ versus $2.37 \pm 0.04 P<0.0001$, O: $1.89 \pm 0.04$ versus $1.85 \pm 0.04$ ). The overall tissue C\% was significantly higher for L. punctata than for $L$. minuta in all experiments (H: $41.08 \pm 0.09$ versus $40.26 \pm 0.65 P<0.0001, \mathrm{E}: 40.91 \pm 0.50$ versus $39.88 \pm 0.46 P<$ $0.05, \mathrm{M}: 42.66 \pm 0.23$ versus $40.98 \pm 0.27 P<0.0001, \mathrm{O}$ : $38.77 \pm 0.52$ versus $37.88 \pm 0.51 P<0.05)$.

Effect of Nutrient Reduction. The overall tissue N\% followed the pattern that was observed for biomass (Figures 3(a) and $3(b)$ ). In both species the tissue N\% was significantly lower when the phosphorus concentration in the medium was reduced from hypereutrophic to eutrophic condition. However, no difference was observed between eutrophic and mesotrophic conditions. The oligotrophic condition, however, impeded both species $\mathrm{N}$ uptake and resulted in a tissue N\% even lower than $2 \%$.

The tissue $\mathrm{C} \%$ showed a different pattern (Figure 3(c)). L. punctata tissue $\mathrm{C} \%$ was similar in hypereutrophic and eutrophic conditions but increased in mesotrophic condition. In oligotrophic condition, however, the $\mathrm{P}$ in the medium was so low that $\mathrm{C}$ uptake was very low. For L. minuta, $\mathrm{C} \%$ remained similar in hypereutrophic, eutrophic, and mesotrophic conditions but was lower in oligotrophic level.

Two-way ANOVA (Table 2) showed that water phosphorus concentration had a significant influence on biomass, $\mathrm{N} \%$, and $\mathrm{C} \%$, while species only had an effect on $\mathrm{C} \%$ and biomass. Species $\mathrm{x}$ phosphorus concentration had a significant influence on all.

3.3. Influence of Nutrient Reduction and Intra- and Interspecific Effects on Species' RGR. Both species showed a declining constant growth rate when phosphorus was reduced (Table 3). In hypereutrophic and eutrophic condition, the RGRs of $L$. minuta and $L$. punctata were affected by negative inter- and intraspecific interactions. This indicates that an increase in either species initial biomass would decrease both species RGR. In mesotrophic condition, the RGR of L. minuta was also influenced by negative intra- and interspecific effects. The opposite, however, was observed for L. punctata RGR, which was influenced by positive intraand interspecific effects, indicating that an increase of either
TABLE 2: Effects of the water phosphorus level $\left(\mathrm{P}_{\mathrm{H}_{2} \mathrm{O}}\right)$, species, and their interaction $\left(\mathrm{P}_{\mathrm{H}_{2} \mathrm{O}}\right.$ * species) on the species $\mathrm{N}$ and $\mathrm{C}$ tissue content and biomass. Figures are $F$-ratios and levels of significance, based on two-way ANOVA with aligned rank transformed (ART) data.

\begin{tabular}{lccc}
\hline & $\mathrm{N}$ & $\mathrm{C}$ & Biomass \\
\hline $\mathrm{P}_{\mathrm{H}_{2} \mathrm{O}}$ & $119.36^{* * * *}$ & $72.19^{* * * *}$ & $63.08^{* * * *}$ \\
Species & $0.90^{\text {n.s. }}$ & $30.84^{* * * *}$ & $419.58^{* * * *}$ \\
$\mathrm{P}_{\mathrm{H}_{2} \mathrm{O}} \times$ species & $9.32^{* * * *}$ & $3.04^{*}$ & $12.05^{* * * *}$ \\
\hline
\end{tabular}

n.s.: nonsignificant, ${ }^{*} P<0.05,{ }^{* * * *} P<0.0001$.

species initial biomass has positive effects on the L. punctata RGR.

3.4. Change in Biomass Composition. The results of the RGRD model showed that a change in biomass composition occurred when L. punctata and L. minuta were grown together, in all conditions except in oligotrophic condition. The negative constant confirmed that a hypereutrophic and eutrophic condition favoured L. minuta, while a nutrient reduction to mesotrophic condition shifted the composition in favour of L. punctata (constant H: -0.0357 , E: $-0.0064, \mathrm{M}$ : $0.0030)$.

\section{Discussion}

4.1. Effect of Nutrient Reduction on Growth. In this study, both species' growth was negatively influenced by the reduction in phosphorus concentration. The average RGRs found in this study are similar to ranges in the literature [40-42]. Several authors observed an effect on plant RGR after a change in nutrients [43-45]. In this study, however, a reduction in phosphorus from eutrophic to mesotrophic condition had no effect on species' biomass production. One reason could be the small difference in phosphorus concentration between the two treatments. This was a possible explanation in the study of Hastwell et al. [46], who observed no change in biomass when reducing nutrients $\left(0.06\right.$ versus $0.12 \mathrm{mg} \mathrm{P} \mathrm{L}^{-1}$, 0.76 versus 1.03 kjeldahl $\mathrm{N} \mathrm{L}^{-1}$ ). However, in other studies biomass production did change when reducing water nutrients to similar concentrations $[47,48]$. This indicates that a reduction in phosphorus from hypereutrophic to eutrophic condition could have a substantial impact on both invasive species growth and spread, though an additional reduction to mesotrophic condition would have no further effect.

4.2. Competition. We hypothesized that the outcome of competition would change with varying phosphorus concentration. Lemna minuta clearly benefited from high phosphorus concentrations, while a reduction to mesotrophic condition favoured L. punctata. A change in species competitive outcome with similar growth form after nutrient reduction was found in several studies [7, 45].

Our results show that competition occurred in every experiment except in oligotrophic condition. In hypereutrophic condition, the RGR of L. punctata was influenced by 

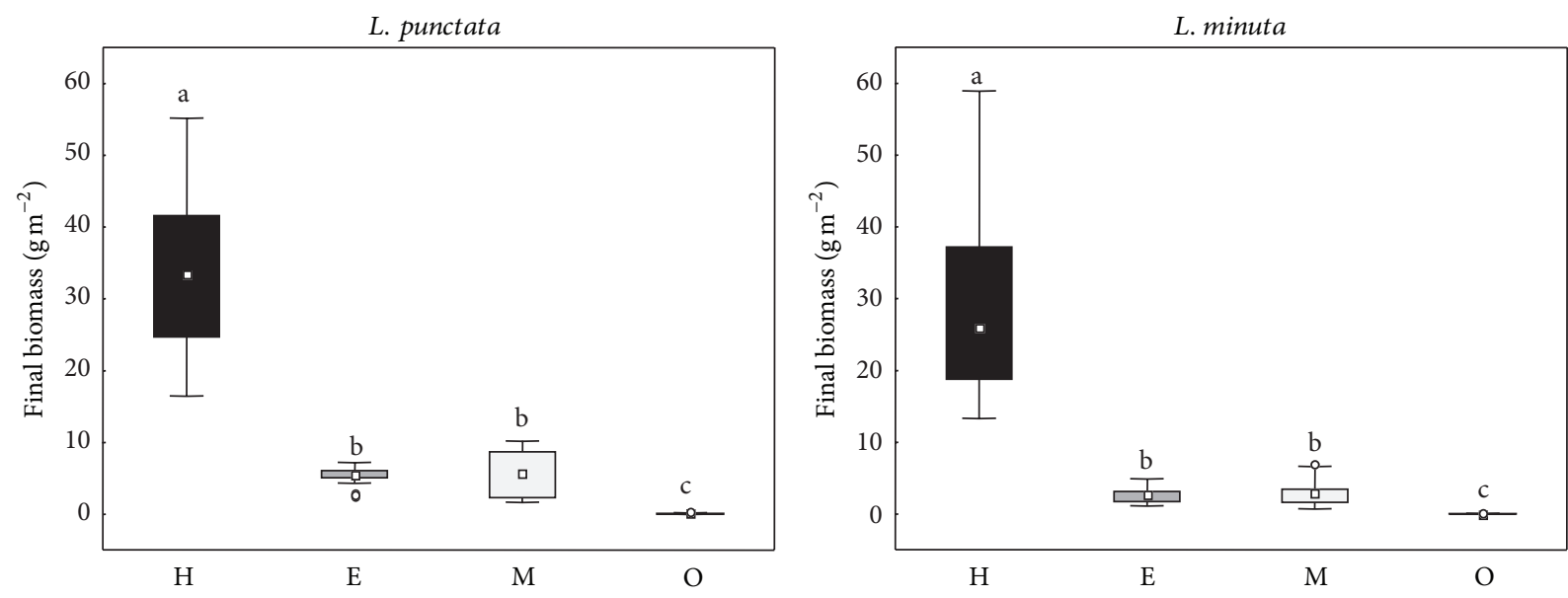

(a)
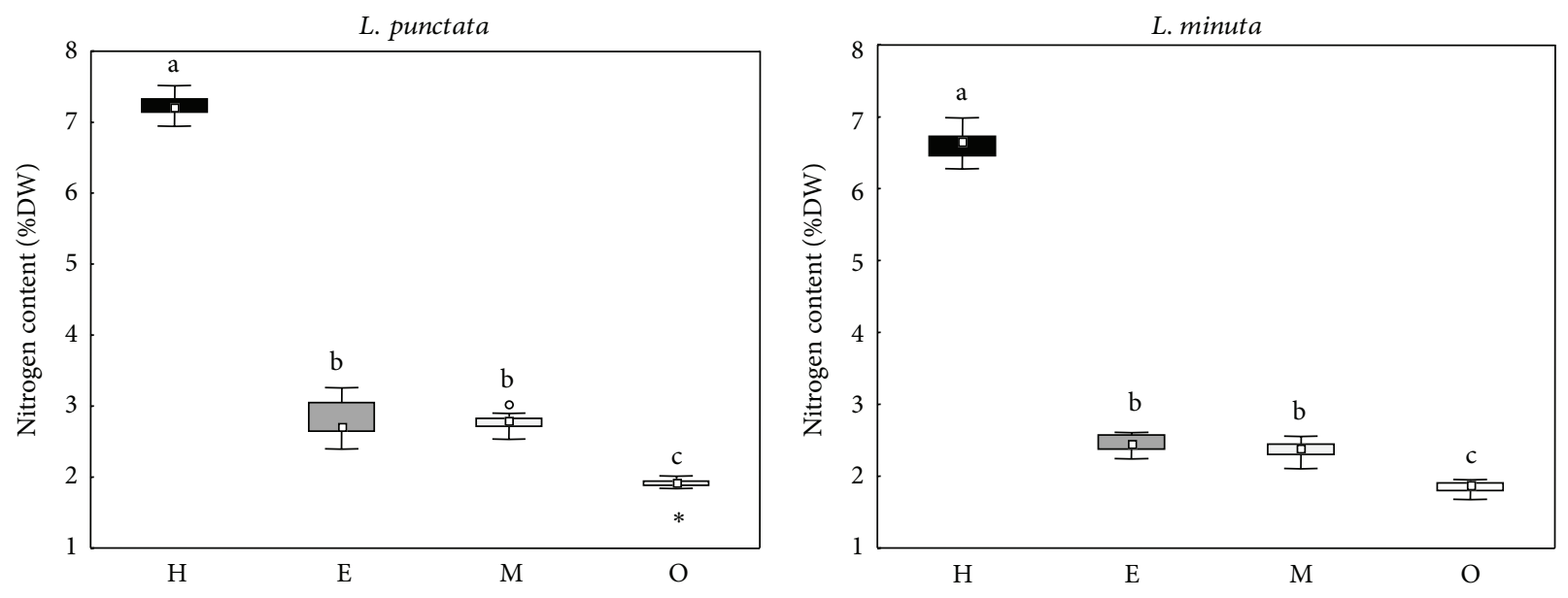

(b)
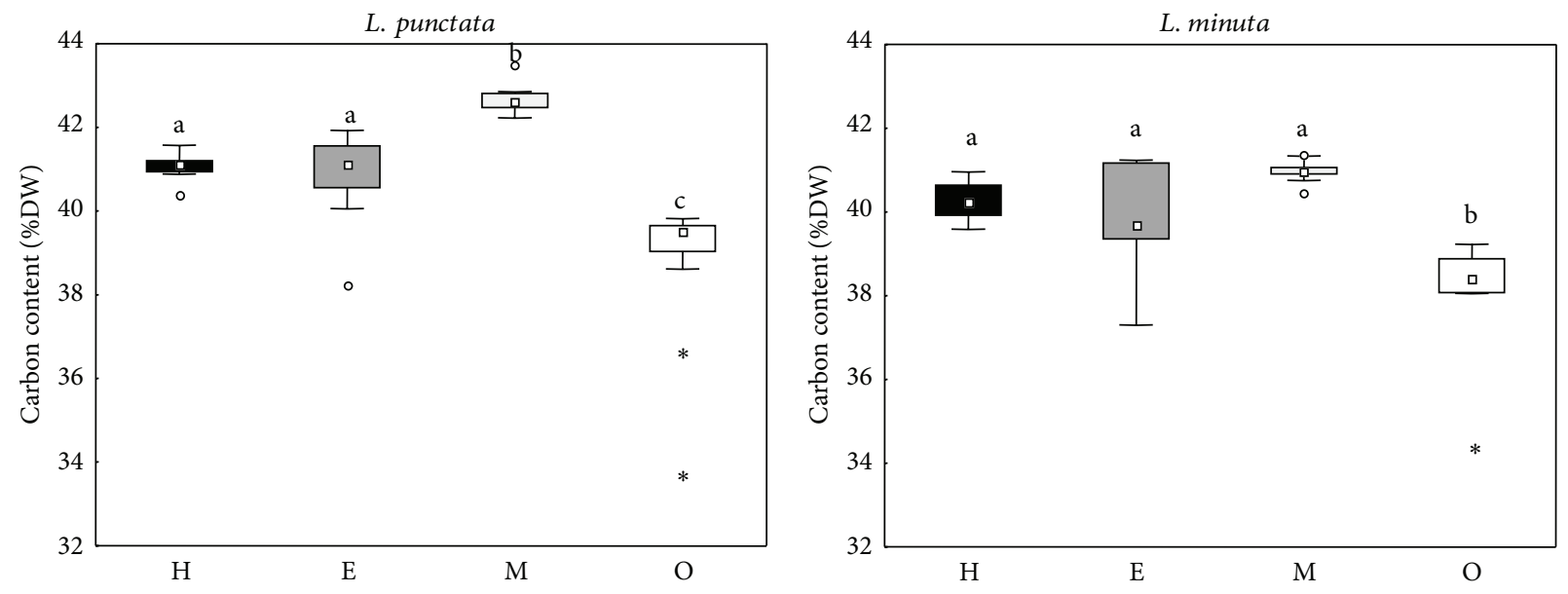

(c)

Figure 3: Final biomass and plant N and C content in L. punctata and L. minuta in hypereutrophic (black), eutrophic (dark grey), mesotrophic (light grey), and oligotrophic (white) conditions. $\square$ represents the median, the box represents the interquartile range, and the vertical lines indicate the minimum and the maximum non-outlier values. Outliers are represented by $\bigcirc$, extremes by $*$. Different letters indicate significant differences between nutrient levels for each species. 
TABLE 3: Linear equations for relative growth rate (RGR) of L. punctata (p) and L. minuta (m) in hypereutrophic (H), eutrophic (E), mesotrophic $(\mathrm{M})$, and oligotrophic $(\mathrm{O})$ conditions. $\left(y_{1}\right)$ represents L. minuta and $\left(y_{2}\right)$ represents L. punctata. Values in bold indicate significant coefficients ${ }^{* * * *} P<0.0001,{ }^{* * *} P<0.001,{ }^{* *} P<0.01,{ }^{*} P<0.05$, n.s.: nonsignificant.

\begin{tabular}{|c|c|c|c|}
\hline Nutrient condition & Linear model & $R^{2}$ & $F$ \\
\hline \multirow{2}{*}{$\mathrm{H}$} & 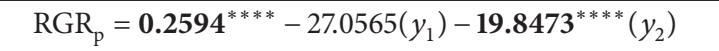 & 0.69 & $F_{2,17}=18.94^{* * * *}$ \\
\hline & $\mathrm{RGR}_{\mathrm{m}}=0.2903^{* * * *}-64.9527^{* * *}\left(y_{1}\right)-20.1793^{* * * *}\left(y_{2}\right)$ & 0.72 & $F_{2,17}=21.9^{* * * *}$ \\
\hline \multirow{2}{*}{$\mathrm{E}$} & $\mathrm{RGR}_{\mathrm{p}}=\mathbf{0 . 1 3 4 5}^{* * * *}-19.6726^{* *}\left(y_{1}\right)-18.7755^{* * * *}\left(y_{2}\right)$ & 0.77 & $F_{2,17}=29.25^{* * * *}$ \\
\hline & $\mathrm{RGR}_{\mathrm{m}}=\mathbf{0 . 1 4 0 8}^{* * * *}-11.9127\left(y_{1}\right)-2.5873\left(y_{2}\right)$ & 0.19 & $F_{2,17}=1.99^{\text {n.s. }}$ \\
\hline \multirow{2}{*}{ M } & 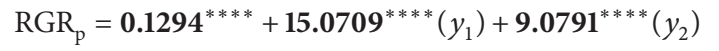 & 0.84 & $F_{2,17}=43.37^{* * * *}$ \\
\hline & 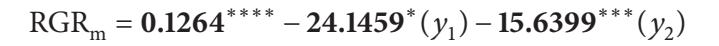 & 0.58 & $F_{2,17}=11.58^{* * *}$ \\
\hline \multirow{2}{*}{$\mathrm{O}$} & 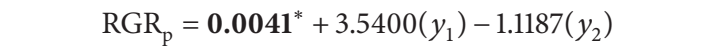 & 0.15 & $F_{2,17}=1.55^{\text {n.s. }}$ \\
\hline & $\mathrm{RGR}_{\mathrm{m}}=\mathbf{0 . 0 0 5 9} 9^{* * *}+2.22600\left(y_{1}\right)-1.26294\left(y_{2}\right)$ & 0.15 & $F_{2,17}=1.55^{\text {n.s. }}$ \\
\hline
\end{tabular}

intraspecific competition. The lack of interspecific competition seems evident since competition is expected to occur when nutrients are in short supply [49]. Since fronds are clustered in groups, competition with conspecific neighbours remains possible. A large reduction in phosphorus to eutrophic condition led to intra- and interspecific competition influencing the growth rate of L. punctata. In mesotrophic conditions, positive effects of both species have been observed on the RGR of L. punctata, which could indicate facilitation. Since only few lemnid competition experiments exist, no facilitative interactions are known in function of nutrients. However, facilitation has been observed by Driever et al. [42] in L. minor, producing mats in which temperature increases, thereby helping other species grow. For L. minuta, if any effects occurred, these were always negative.

4.3. Strategies. Even though L. punctata and L. minuta possess many similarities, their behaviour differed when facing competition. L. punctata did not change its strategy when facing competition. L. minuta, however, produced less total fronds, thereby covering a smaller total area. Even though a phosphorus reduction from eutrophic to mesotrophic condition induced no change in either RGR, frond morphology, or number, both species produced clusters consisting of more fronds. Although biomass allocation to roots is often observed at low nutrient supply [50], the root length of both species decreased when phosphorus was reduced. This can be explained by the fact that growth of meristematic tissue and especially root growth is associated with $\mathrm{P}$ and that increasing $\mathrm{P}$ promotes root growth [51]. In addition, lemnids are able to take up nutrients by the leaves [26]. Clusters consisting of more fronds could result in a larger contact surface with the water to maximize nutrient uptake.

\subsection{Effect of Nutrient Reduction on Tissue Nutrient Content.} The result that high phosphorus concentrations favour $L$. minuta, while lowering the concentration favours L. punctata, is supported by the nutrient tissue content, showing that in all conditions except for oligotrophic, L. punctata was able to store more $\mathrm{N}$ and $\mathrm{C}$ than L. minuta. Our N\% and C\% results concur with percentages found in other studies for $L$. minuta and L. punctata, as well as other related lemnid species $[50,52,53]$.

We found that $\mathrm{P}$ stress resulted in a lowered uptake of $\mathrm{N}$ and a stable or slight increase in $\mathrm{C}$. Interactions between nutrients in tissue have been observed by other authors [54-56]; however, few elucidated on this. According to Xu et al. [50] an increase in carbon content in low nutrients could be due to the duckweed's starch production. However, Chapin [57] found similar results in N-stressed plants with lowered tissue $\mathrm{P}$ and increased C. Our results can similarly be explained by the fact that a nutrient limitation leads to a growth reduction and therefore a lower carbon need. Since photosynthesis continues, an accumulation of unused carbohydrates occurs. To match the plant's lower $\mathrm{C}$ requirement, photosynthesis declines, thereby reducing the amount of $\mathrm{N}$ needed which lowers the $\mathrm{N}$ uptake [57].

\section{Conclusions}

Lemnids are mostly controlled by mechanical removal; however, these tiny plants are never removed entirely and can rapidly cover a pond again due to their high turnover rates. Environmental control such as nutrient reduction is therefore needed to affect the species growth rates. Our results show that L. minuta and L. punctata are able to invade a wide variety of habitats ranging in trophic condition; however, a water column phosphorus reduction from hypereutrophic to eutrophic condition already induces a significant decrease in growth rates. Water quality targets should therefore be implemented and further studied [31]. The study of nutrient targets however should be species-based [58] to assure an effective control of individual freshwater species since different species can react differently to changed nutrient conditions. We can conclude that a $100 \mu \mathrm{g} \mathrm{P} \mathrm{L}^{-1}$ is a realistic goal for pond managers to achieve and to reduce Lemna cover.

We also found L. punctata to outcompete the very invasive L. minuta at lower nutrient conditions, emphasizing that the former species might become even more abundant if not carefully monitored. However, since its ecology hardly differs from L. minuta and native duckweed, this species will probably not become invasive [30]. Due to the widespread nonnative distribution of L. minuta and the species' impact, 
we advise that L. minuta should be added to Invasive Alien Species lists of European countries, as is the case for Belgium, and considered for management.

\section{Conflict of Interests}

The authors declare that there is no conflict of interests regarding the publication of this paper.

\section{Acknowledgments}

The authors would like to thank D. Maes, N. Brion, T Sierens, and K. Van Eyndonck. This Ph.D. research is funded by a scholarship provided by the government agency for Innovation by Science and Technology and by the Vrije Universiteit Brussel (BAS42).

\section{References}

[1] C. S. James, J. W. Eaton, and K. Hardwick, "Competition between three submerged macrophytes, Elodea canadensis Michx, Elodea nuttallii (Planch.) St John and Lagarosiphon major (Ridl.) Moss," Hydrobiologia, vol. 415, pp. 35-40, 1999.

[2] M.-H. Barrat-Segretain and A. Elger, "Experiments on growth interactions between two invasive macrophyte species," Journal of Vegetation Science, vol. 15, no. 1, pp. 109-114, 2004.

[3] J. H. Burns, "A comparison of invasive and non-invasive dayflowers (Commelinaceae) across experimental nutrient and water gradients," Diversity and Distributions, vol. 10, no. 5-6, pp. 387-397, 2004.

[4] E. Grotkopp and M. Rejmánek, "High seedling relative growth rate and specific leaf area are traits of invasive species: phylogenetically independent contrasts of woody angiosperms," American Journal of Botany, vol. 94, no. 4, pp. 526-532, 2007.

[5] B. Gopal and U. Goel, "Competition and allelopathy in aquatic plant communities," The Botanical Review, vol. 59, no. 3, pp. 155210, 1993.

[6] D. M. Cahill, J. E. Rookes, B. A. Wilson, L. Gibson, and K. L. McDougall, "Turner review no. 17. Phytophthora cinnamomi and Australia's biodiversity: impacts, predictions and progress towards control," Australian Journal of Botany, vol. 56, no. 4, pp. 279-310, 2008.

[7] T. K. Van, G. S. Wheeler, and T. D. Center, "Competition between Hydrilla verticillata and Vallisneria americana as influenced by soil fertility," Aquatic Botany, vol. 62, no. 4, pp. 225233, 1999 .

[8] C. C. Daehler, "Performance comparisons of co-occurring native and alien invasive plants: implications for conservation and restoration," Annual Review of Ecology, Evolution, and Systematics, vol. 34, pp. 183-211, 2003.

[9] M. A. Davis, J. P. Grime, and K. Thompson, "Fluctuating resources in plant communities: a general theory of invasibility," Journal of Ecology, vol. 88, no. 3, pp. 528-534, 2000.

[10] V. H. Smith, G. D. Tilman, and J. C. Nekola, "Eutrophication: impacts of excess nutrient inputs on freshwater, marine, and terrestrial ecosystems," Environmental Pollution, vol. 100, no. 13, pp. 179-196, 1998.

[11] D. W. Schindler, "Evolution of phosphorus limitation in lakes," Science, vol. 195, no. 4275, pp. 260-262, 1977.
[12] A. N. Sharpley, T. Daniel, T. Sims, J. Lemunyon, R. Stevens, and R. Parry, Agricultural Phosphorus and Eutrophication, U.S. Department of Agriculture, Agricultural Research Service, 2nd edition, 2003.

[13] D. L. Correll, "The role of phosphorus in the eutrophication of receiving waters: a review," Journal of Environmental Quality, vol. 27, no. 2, pp. 261-266, 1998.

[14] E. C. Adair, I. C. Burke, and W. K. Lauenroth, "Contrasting effects of resource availability and plant mortality on plant community invasion by Bromus tectorum L," Plant and Soil, vol. 304, no. 1-2, pp. 103-115, 2008.

[15] J. L. Funk and P. M. Vitousek, "Resource-use efficiency and plant invasion in low-resource systems," Nature, vol. 446, no. 7139, pp. 1079-1081, 2007.

[16] G. Fogarty and J. M. Facelli, "Growth and competition of Cytisus scoparius, an invasive shrub, and Australian native shrubs," Plant Ecology, vol. 144, no. 1, pp. 27-35, 1999.

[17] C. L. Gaudet and P. A. Keddy, "Competitive performance and species distribution in shoreline plant communities: a comparative approach," Ecology, vol. 76, no. 1, pp. 280-291, 1995.

[18] C. Garbey, K. J. Murphy, G. Thiébaut, and S. Muller, "Variation in P-content in aquatic plant tissues offers an efficient tool for determining plant growth strategies along a resource gradient," Freshwater Biology, vol. 49, no. 3, pp. 346-356, 2004.

[19] P. Pysek and D. M. Richardson, "Traits associated with invasiveness in alien plants: where do we stand?" in Biological Invasions, W. Nentwig, Ed., vol. 193, pp. 97-125, Springer, Berlin, Germany, 2007.

[20] M.-H. Barrat-Segretain, A. Elger, P. Sagnes, and S. Puijalon, "Comparison of three life-history traits of invasive Elodea canadensis Michx. and Elodea nuttallii (Planch.) H. St. John," Aquatic Botany, vol. 74, no. 4, pp. 299-313, 2002.

[21] Y. Feng, J. Wang, and W. Sang, "Biomass allocation, morphology and photosynthesis of invasive and noninvasive exotic species grown at four irradiance levels," Acta Oecologica, vol. 31, no. 1, pp. 40-47, 2007.

[22] Y.-L. Feng and G.-L. Fu, "Nitrogen allocation, partitioning and use efficiency in three invasive plant species in comparison with their native congeners," Biological Invasions, vol. 10, no. 6, pp. 891-902, 2008.

[23] R. Portielje and R. M. Roijackers, "Primary succession of aquatic macrophytes in experimental ditches in relation to nutrient input," Aquatic Botany, vol. 50, no. 2, pp. 127-140, 1995.

[24] R. A. Janes, J. W. Eaton, and K. Hardwick, "The effects of floating mats of Azolla filiculoides lam. and Lemna minuta Kunth on the growth of submerged macrophytes," Hydrobiologia, vol. 340, no. 1-3, pp. 23-26, 1996.

[25] M. E. Hernandez and W. J. Mitsch, "Deepwater macrophytes and water quality in two experimental constructed wetlands at Olentangy River Wetland Research Park," in Deepwater Vegetation and Water Quality, pp. 45-50, 2004.

[26] E. Landolt and R. Kandeler, The Family of Lemnaceae-A Monographic Study, Volume 2, Veröffentlichungen des Geobotanischen Institutes der Eidg. Techn. Hochschule, Stiftung Rübel , Zurich, Switzerland, 1987.

[27] J. M. Novak and A. S. K. Chan, "Development of P-hyperaccumulator plant strategies to remediate soils with excess $\mathrm{P}$ concentrations," Critical Reviews in Plant Sciences, vol. 21, no. 5, pp. 493-509, 2002.

[28] J. Lambinon, J. E. de Langhe, L. Delvosalle, and J. Duvigneaud, Flora van Belgie, het Groothertogdom Luxemburg, 
Noord-Frankrijk en de aangrenzende gebieden (Pteridofyten en Spermatofyten), National Botanical Garden, Meise, Belgium, 1998.

[29] E. Landolt, The Family of Lemnaceae-A Monographic Study. Volume 1, Veröffentlichungen des Geobotanischen Institutes der Eidg. Techn. Hochschule, Stiftung Rübel, Zurich, Switzerland, 1986.

[30] J. L. C. H. van Valkenburg and R. Pot, "Landoltia punctata (G.Mey.) D.H.Les \& D.J.Crawford (Smal kroos), nieuw voor Nederland," Gorteria, vol. 33, pp. 41-49, 2008.

[31] P. A. Chambers, C. Vis, R. B. Brua, M. Guy, J. M. Culp, and G. A. Benoy, "Eutrophication of agricultural streams: defining nutrient concentrations to protect ecological condition," Water Science and Technology, vol. 58, no. 11, pp. 2203-2210, 2008.

[32] C. Bronmark and L. A. Hanssen, The Biology of Lakes and Ponds, Oxford University Press, Oxford, UK, 2nd edition, 2005.

[33] R. Hoagland and I. Arnon, "The water-culture method for growing plants without soil," Circular, vol. 347, pp. 1-32, 1950.

[34] C. J. T. Spitters, "An alternative approach to the analyses of mixed cropping experiments. 1. Estimation of competition effects," Netherlands Journal of Agricultural Science, vol. 31, pp. $1-11,1983$.

[35] H. E. Nilsson, "Remote sensing and image analysis in plant pathology," Annual Review of Phytopathology, vol. 33, pp. 489527, 1995.

[36] L. C. Purcell, "Soybean canopy coverage and light interception measurements using digital imagery," Crop Science, vol. 40, no. 3, pp. 834-837, 2000.

[37] J. Nieuwenhuize, Y. E. M. Maas, and J. J. Middelburg, "Rapid analysis of organic carbon and nitrogen in particulate materials," Marine Chemistry, vol. 45, no. 3, pp. 217-224, 1994.

[38] J. Connolly and P. Wayne, "Assessing determinants of community biomass composition in two-species plant competition studies," Oecologia, vol. 142, no. 3, pp. 450-457, 2005.

[39] B. C. Hwang and W. K. Lauenroth, "Effect of nitrogen, water and neighbor density on the growth of Hesperis matronalis and two native perennials," Biological Invasions, vol. 10, no. 5, pp. 771779, 2008.

[40] L. T. Valderrama, C. M. del Campo, C. M. Rodriguez, L. E. DeBashan, and Y. Bashan, "Treatment of recalcitrant wastewater from ethanol and citric acid production using the microalga Chlorella vulgaris and the macrophyte Lemna minuscula," Water Research, vol. 36, no. 17, pp. 4185-4192, 2002.

[41] N. Cedergreen and T. V. Madsen, "Light regulation of root and leaf NO3- uptake and reduction in the floating macrophyte Lemna minor," New Phytologist, vol. 161, no. 2, pp. 449-457, 2004.

[42] S. M. Driever, E. H. van Nes, and R. M. M. Roijackers, "Growth limitation of Lemna minor due to high plant density," Aquatic Botany, vol. 81, no. 3, pp. 245-251, 2005.

[43] I. Woo and J. B. Zedler, "Can nutrients alone shift a sedge meadow towards dominance by the invasive Typha $\times$ glauca?" Wetlands, vol. 22, no. 3, pp. 509-521, 2002.

[44] S. Szabó, R. Roijackers, M. Scheffer, and G. Borics, "The strength of limiting factors for duckweed during algal competition," Archiv fur Hydrobiologie, vol. 164, no. 1, pp. 127-140, 2005.

[45] J. Njambuya, I. Stiers, and L. Triest, "Competition between Lemna minuta and Lemna minor at different nutrient concentrations," Aquatic Botany, vol. 94, no. 4, pp. 158-164, 2011.

[46] G. T. Hastwell, A. J. Daniel, and G. Vivian-Smith, "Predicting invasiveness in exotic species: do subtropical native and invasive exotic aquatic plants differ in their growth responses to macronutrients?" Diversity and Distributions, vol. 14, no. 2, pp. 243-251, 2008

[47] G. Rubio, J. Zhu, and J. P. Lynch, "A critical test of the two prevailing theories of plant response to nutrient availability," American Journal of Botany, vol. 90, no. 1, pp. 143-152, 2003.

[48] R. M. Wersal and J. D. Madsen, "Comparative effects of water level variations on growth characteristics of Myriophyllum aquaticum," Weed Research, vol. 51, no. 4, pp. 386-393, 2011.

[49] R. Aerts, "Interspecific competition in natural plant communities: mechanisms, trade-offs and plant-soil feedbacks," Journal of Experimental Botany, vol. 50, no. 330, pp. 29-37, 1999.

[50] J. Xu, W. Cui, J. J. Cheng, and A.-M. Stomp, "Production of highstarch duckweed and its conversion to bioethanol," Biosystems Engineering, vol. 110, no. 2, pp. 67-72, 2011.

[51] S. I. Tisdale, W. L. Nelson, and J. D. Beaton, Soil Fertility and Fertilizers, Macmillan, New York, NY, USA, 1985.

[52] B. A. Fulton, R. A. Brain, S. Usenko, J. A. Back, R. S. King, and B. W. Brooks, "Influence of nitrogen and phosphorus concentrations and ratios on Lemna gibba growth responses to triclosan in laboratory and stream mesocosm experiments," Environmental Toxicology and Chemistry, vol. 28, no. 12, pp. 2610-2621, 2009.

[53] L. Kufel, M. Strzałek, U. Wysokińska, E. Biardzka, S. Oknińska, and K. Ryś, "Growth rate of duckweeds (Lemnaceae) in relation to the internal and ambient nutrient concentrations û testing the droop and monod models," Polish Journal of Ecology, vol. 60, pp. 241-249, 2012.

[54] T.-H. Kim, W.-J. Jung, B.-R. Lee, T. Yoneyama, H.-Y. Kim, and K.-Y. Kim, "P effects on $\mathrm{N}$ uptake and remobilization during regrowth of Italian ryegrass (Lolium multiflorum)," Environmental and Experimental Botany, vol. 50, no. 3, pp. 233242, 2003.

[55] S. Güsewell, "Nutrient resorption of wetland graminoids is related to the type of nutrient limitation," Functional Ecology, vol. 19, no. 2, pp. 344-354, 2005.

[56] M. A. Hussaini, V. B. Ogunlela, A. A. Ramalan, and A. M. Falaki, "Mineral composition of dry season maize (Zea mays L.) in response to varying levels of nitrogen, phosphorus and irrigation at Kadawa, Nigeria," World Journal of Agricultural Sciences, vol. 4, pp. 775-780, 2008.

[57] F. S. Chapin, "Integrated responses of plants to stress," BioScience, vol. 41, pp. 29-36, 1991.

[58] I. Clarke, Z. Stokes, and R. Wallace, "Habitat Restoration Planning Guide for Natural Resource Managers," 2010, http://www .environment.sa.gov.au/Home. 

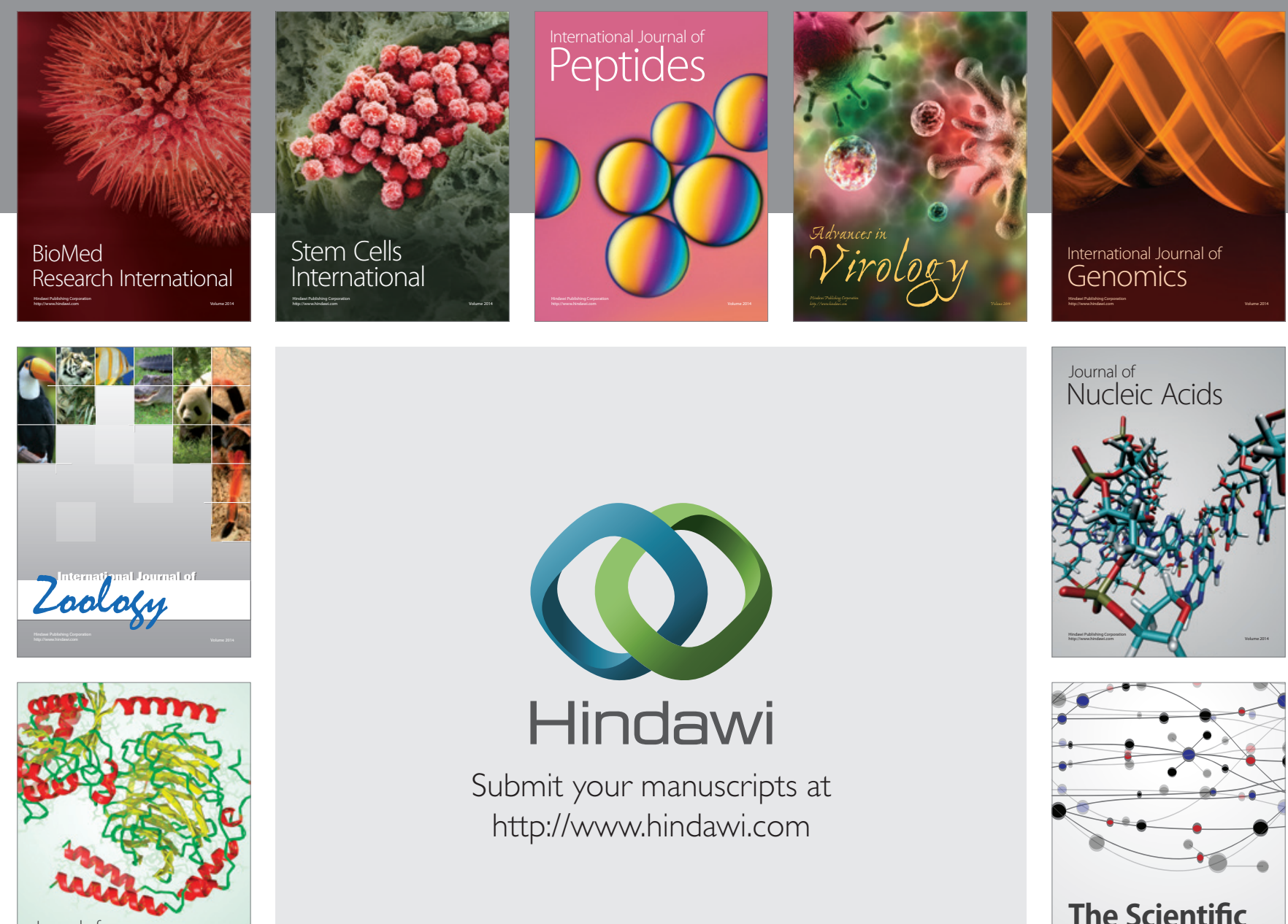

Submit your manuscripts at

http://www.hindawi.com

Journal of
Signal Transduction
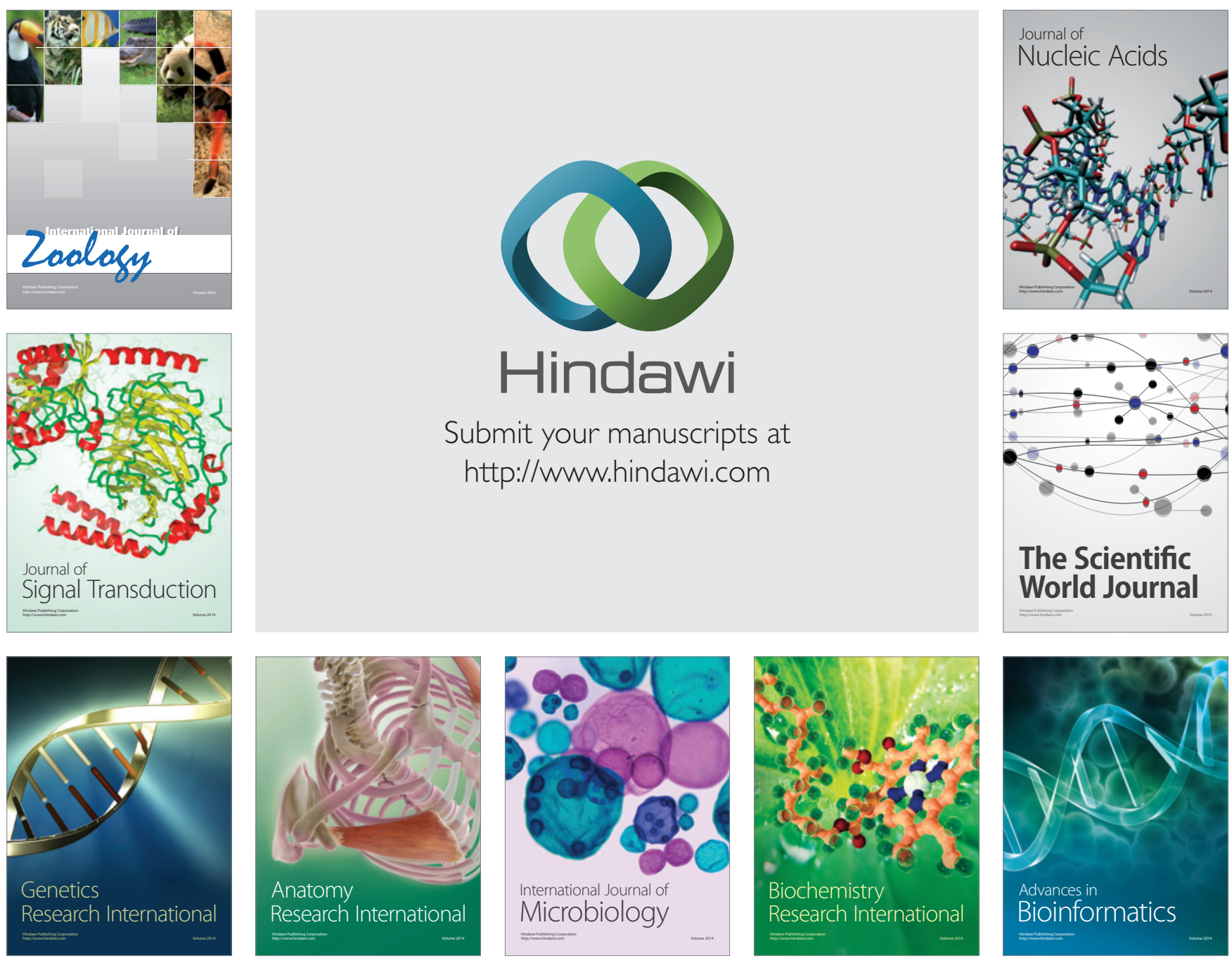

The Scientific World Journal
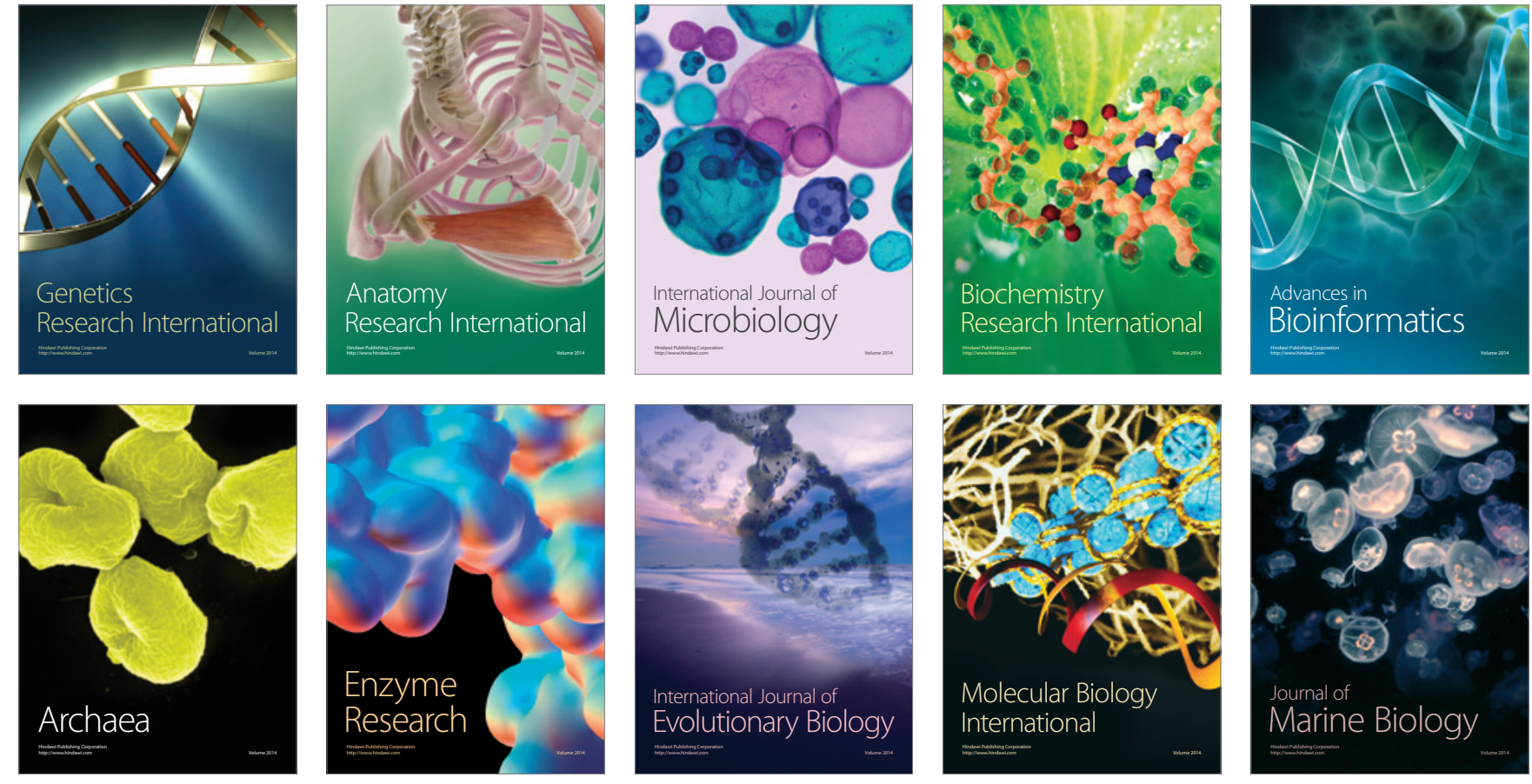